Editorial

\title{
NEET Super-Specialty Intake: A Paradox of Demand and Supply or the Eligibility?
}

\section{Dinesh Kadam ${ }^{1}$}

${ }^{1}$ Department of Plastic and Reconstructive Surgery, A J Institute of Medical Sciences and A J Hospital and Research Centre, Mangalore, Karnataka, India

Indian J Plast Surg:2021;54:1-3.

In 1999, at Postgraduate Institute of Medical Education and Research (PGIMER) Chandigarh, the postdoctoral course entrance examination to $\mathrm{DM} / \mathrm{MCh}$ witnessed an unusual situation. Generally, to qualify for the final interview, a candidate must secure a minimum of $50 \%$ marks. Unexpectedly, most of the toppers fell short of it by fractions, and in some specialties, none qualified. Typically, no seat goes vacant for want of performance at this highly competitive examination. There could have been issues related to question paper standards or the evaluation pattern of multiple responses, etc., which most felt. However, the institute, true to its reputation, refused to grant grace marks by stating that "if the candidates do not meet our standards, we do not want them!" Consequently, only a handful of postgraduates could join, including those in plastic surgery. In 2021, the situation seems similar to the vacancies at the national eligibility cum entrance test (NEET) for superspecialty (SS); the reasons, however, are different, and that is what I intend to highlight and discuss.

The NEET SS (2020-21) for DM, MCh, and DNB courses was recently concluded, albeit with pandemic delays. As many as 428 seats remained vacant despite reducing the qualification percentile in mop-up rounds. In plastic surgery alone, 28 seats out of 249 remained unclaimed. ${ }^{1}$

Several factors possibly are responsible for this enormous wastage, such as candidate's preference for specialty and institution, mandatory service bond or hefty penalty, variations in stipend and fee structure in private institutes, increased number of seats and, finally, NEET eligibility versus the number of available seats for the applicants. I believe there are serious disadvantages to the 50th percentile eligibility that must be reconsidered.
A quick look at the seat matrix and the number of candidates appearing in each MCh/DNB surgical superspecialty indicates toward the demand-supply equations $(\text { - Table 1) })^{2,3}$ Every year, over 3600 general surgery postgraduates and those from other broad specialties complete their training and apply for over 2000 M.Ch./DNB seats both in NEET and autonomous institutes. However, the criterion of 50th percentile limits aspiring postgraduates, where half of them are considered ineligible and remain excluded.

\section{Perils of Percentile Eligibility}

The 50th percentile is simply the median of all students' highest and lowest scores. Based on their relative performance, only $50 \%$ will become eligible, and the remainder, regardless of overall performance is eliminated.

Last year, over 5200 students appeared for NEET SS, with two optional specialties for the $1835 \mathrm{MCh}$ and DNB seats (-Table 2). ${ }^{4}$ Taking into consideration the 50th percentile as eligibility, a little over 2600 candidates qualified, each with an alternative option. Further, the preference and distribution of students varied considerably among the specialties. Seventy percent of the candidates opted for surgical gastroenterology, surgical oncology and urology, 20\% for plastic and neurosurgery, and only $10 \%$ for cardiothoracic and pediatric surgery. While the number of qualified was just adequate for the seats available, many specialties lacked enough eligible candidates.

In plastic and reconstructive surgery, there were 958 candidates for 249 seats. Half were eliminated in the 50th percentile eligibility criteria, and assuming that everyone had an alternative choice, the number got further reduced to $25 \%$.

\footnotetext{
Address for correspondence Dr. Dinesh Kadam, MS, DNB, MCh, Professor and Head, Department of Plastic and Reconstructive Surgery, A J Institute of Medical Sciences and A J Hospital and Research Centre, Mangalore-575004, Karnataka, India (e-mail: drkadam@yahoo.co.in).
}

DOI https://doi.org/ $10.1055 / \mathrm{s}-0041-1728236$ ISSN 0970-0358

(C)2021. Association of Plastic Surgeons of India.

This is an open access article published by Thieme under the terms of the Creative Commons Attribution-NonDerivative-NonCommercial-License, permitting copying and reproduction so long as the original work is given appropriate credit. Contents may not be used for commercial purposes, or adapted, remixed, transformed or built upon. (https://creativecommons.org/licenses/by-nc-nd/4.0/). Thieme Medical and Scientific Publishers Pvt. Ltd. A-12, 2nd Floor, Sector 2, Noida-201301 UP, India 
Table 1 Total DM/MCh seats under NMC and autonomous institutions

\begin{tabular}{|l|l|l|l|}
\hline NMC (previous MCI)/deemed Universities/AlIMS/PGI & Govt. & Pvt. & Total \\
\hline MCh & 1654 & 366 & 2020 \\
\hline DM & 1859 & 475 & 2334 \\
\hline All DM/MCh & 3513 & 841 & 4354 \\
\hline No. of colleges offering courses & 117 & 61 & 178 \\
\hline
\end{tabular}

Abbreviation: NMC, national medical commission.

Table 2 The seat matrix for NEET SS 2020 applicants

\begin{tabular}{|c|c|c|c|c|c|c|c|c|c|}
\hline \multirow{2}{*}{$\begin{array}{l}\text { Specialty } \\
\text { Surgical } \\
\text { superspecialties }\end{array}$} & \multirow{2}{*}{$\begin{array}{l}\text { Appeared } \\
\text { for NEET a } \\
\text { No. of } \\
\text { candidates } \\
\times 2\end{array}$} & \multicolumn{3}{|c|}{$\begin{array}{l}\text { Total seats under NEET: } \\
\text { MCh/DNB }\end{array}$} & \multicolumn{4}{|c|}{ Autonomous institutions not under NEET } & \multirow{2}{*}{$\begin{array}{l}\text { Eligible } \\
\text { students vs. } \\
\text { seat ratioc }\end{array}$} \\
\hline & & $\begin{array}{l}\text { MCh/DNB } \\
\text { combined }\end{array}$ & $\mathrm{MCh}$ & DNB & $\begin{array}{l}\text { AllMS, } \\
\text { Delhi and } \\
\text { others }\end{array}$ & $\begin{array}{l}\text { AllMS, } \\
\text { Rishikesh } \\
\text { alone }\end{array}$ & PGI & JIPMER & \\
\hline Plastic surgery & 958 & 249 & 228 & 21 & 23 & 22 & 10 & 2 & 1.9:1 \\
\hline Neurosurgery & 955 & 349 & 285 & 64 & 33 & 20 & 12 & 4 & $1.3: 1$ \\
\hline Urology & 2214 & 424 & 307 & 117 & 13 & 22 & 10 & 3 & $2.6: 1$ \\
\hline Pediatric surgery & 447 & 185 & 179 & 6 & 19 & 14 & 8 & 2 & $1.2: 1$ \\
\hline $\begin{array}{l}\text { Surgical } \\
\text { gastroenterology }\end{array}$ & 2411 & 173 & 119 & 54 & 17 & 20 & & & $6.9: 1$ \\
\hline $\begin{array}{l}\text { Cardiothoracic } \\
\text { and vascular } \\
\text { surgery }\end{array}$ & 527 & 210 & 188 & 22 & 32 & 18 & 12 & 3 & $1.2: 1$ \\
\hline Surgical oncology & 2314 & 212 & 128 & 84 & 19 & 22 & 0 & 3 & $5.4: 1$ \\
\hline $\begin{array}{l}\text { Endocrine } \\
\text { surgery/breast }\end{array}$ & 211 & 10 & 10 & & & 10 & & & 10.5:1 \\
\hline Hand surgery & 136 & 10 & 4 & 6 & Trauma 10 & & & & $6.8: 1$ \\
\hline $\begin{array}{l}\text { Head and neck } \\
\text { surgery }\end{array}$ & 397 & 13 & & & 2 & 13 & & & 15.2:1 \\
\hline Total & 10,570 & 1835 & 1448 & 374 & 143 & $285^{b}$ & 52 & 20 & \\
\hline
\end{tabular}

Abbreviations: NEET, national eligibility cum entrance test; NBE, national board of examinations; NMC, national medical commission; SS, superspecialty.

a Each student can appear for two NEET subjects of choice.

${ }^{\mathrm{b}}$ Several other new branches are not listed here.

'Each student still has two options to choose from, thus further reducing the ratio.

The data presented is a compilation from various sources of NBE/NMC.

The numbers are derived from the results declared, assuming each had two options and the 50 th percentile was $50 \%$ of students.

A simple arithmetic calculation shows that only 239 students were available to stake their claim for 249 seats, excluding $75 \%$ from the pool! Eventually, 28 seats remained unfilled, with most in private colleges, having 54 seats altogether. The National Medical Commission (NMC) data indicate that $20 \%$ of all DM/MCh courses are in private institutions. In the absence of an adequate number of candidates, the colleges that cannot match the stipend and fee structure of government institutions lose the most. Recently, there has been a steep rise in DM/MCh seats in autonomous institutions which are not under the NEET but are open to the same pool of candidates. The AIIMS Rishikesh, established in 2012, has $285 \mathrm{MCh}$ (22 in plastic surgery) and 282 DM courses with several "start up" departments, much more than over the five decades-old AIIMS Delhi (143 MCh seats), PGIMER Chandigarh (52 MCh seats), and JIPMER Puducherry (20 MCh seats).
The percentile calculation is affected by the number of seats, applicants, relative performances, level of complexity of the test paper, etc. The actual qualifiers may vary if the number of equal scores is higher. In undergraduate and postgraduate NEET, the cutoff percentage was strikingly low at $20.4 \%$ and $30.5 \%$, respectively. ${ }^{5,6}$ On the contrary, the average score in surgical superspecialties was $49.5 \%$, much better than the UG and PG level. Thus, notwithstanding the actual percentage of marks obtained, the 50th percentile removes almost half the students, which is perhaps appropriate for UG/PG level where 1.4 million apply for 2 lakh seats in all health systems. For the NEET SS, the current criterion is counterproductive, as it eliminates instead of including all deserving students.

What defines the merit and, thereby, the eligibility at the 50th percentile remains a moot question. It is not persuasive 
to assume that a postgraduate with an MS qualification suddenly becomes untrainable for an MCh unless he or she meets the percentile criteria. Nonetheless, it must avoid wastage of seats when the candidates with good scores are available, and similarly, the check should be on poorly scoring candidates satisfying the eligibility.

\section{Alternatives Options}

In almost all recent NEETs, NMC has lowered the cutoff by 5 to $10 \%$ to counsel vacant seats. The data of NMC itself suggests there are not enough candidates for a seat. Instead, a dynamic cutoff percentile such as 60th, 50th, 40th, etc., could be considered upfront for each examination, based on the number of candidates, available seats, and performance level. Alternatively, seat allotment based on a simple ranking system should serve the same purpose without diluting the merit. By doing away with percentile criteria, "ineligible" candidates with good scores may get a chance to take up vacant seats, which is a win-win situation for everyone.

It is perhaps the time to consider the 6-year direct courses as a worthy option. The introduction of more 6-year M.Ch courses after the MBBS will broaden the eligibility and help the students get into a focused area early on in their career. This also avoids an arduous "learn-unlearn-relearn" cycle, interruption of entrance tests, and mandatory rural services between academic training. The model existing in pediatrics and neurosurgery in central institutes, and many DNB courses deserve to be adopted on a larger scale.

There is no denying that broad surgical specialty postgraduates require additional supervised training to improve their skills and potential. Postdoctoral courses serve this purpose well and offer a prospect for higher training in a chosen field. The fact remains that we are a resource-constrained state where medical specialists are far from adequate for the population. There are barely 2,500 plastic surgeons for the country of 1.36 billion people, an abysmal ratio of one to 5.5 lakh. Out of 554 medical colleges in India, 70\% do not have any superspecialty courses, and only 86 institutes offer plastic surgery training. In such a scenario, the squandering of seats is unaffordable; depriving young aspiring postgraduates of an additional training opportunity is unfortunate, unwarranted, and requires quick redressal.

\section{Conflict of Interest and Declaration}

None declared.

\section{References}

1 Ministry of health and family welfare. Available at: https:// www.mcc.nic.in/MCCSS/SeatMatrix.aspx. Last accessed March 22,2021

2 National medical commission. Available at: https://www. nmc.org.in/information-desk/college-and-course-search. Last accessed February 20, 2021

3 National board of examinations. Available at: https://accr.natboard.edu.in/online_user/frontpage.php? $\mathrm{v}=4$. Last accessed March 22, 2021

4 National board of examinations. Available at: https://cdn3. digialm.com//EForms/configuredHtml/1815/65870/Index. html. Last accessed March 22, 2021

5 Collegedunia. Available at: https://collegedunia.com/exams/ neet-pg/results. Last accessed March 22, 2021

6 Shiksha. Available at: https://www.shiksha.com/medicinehealth-sciences/neet-exam-cutoff. Last accessed March 22, 2021 